\title{
CHANGES IN LIVER GLYCOGEN STUDIED BY THE NEEDLE ASPIRATION TECHNIC IN PATIENTS WITH DIABETIC KETOSIS. WITH A METHOD FOR THE ESTIMATION OF GLYCOGEN FROM HISTOLOGIC PREPARATIONS ${ }^{1}$
}

\author{
By PHILIP K. BONDY, WALTER H. SHELDON, AND LILLIAN D. EVANS
}

(From the Departments of Medicine and Pathology, Emory University School of Medicine, and Grady Memorial Hospital, Atlanta, Ga.)

(Received for publication March 16, 1949)

Previous attempts to estimate the glycogen content of the human liver were based on determinations performed on material obtained by operative biopsy or from postmortem specimens. Observations on animals have shown that these procedures may introduce an important error through the effect of the commonly used anesthetic agents, or of trauma, before the specimen is obtained. The development of a technic for the removal of small specimens of liver by aspiration biopsy is well adapted to the study of glycogen metabolism, for it avoids the uncertain effects of premedication, general anesthesia and the trauma of operation. By this method serial biopsies of the liver have been obtained in a study of patients under treatment for diabetic acidosis.

\section{METHODS}

Liver tissue was obtained by needle biopsy, using the Vim-Silverman needle, under local procaine infiltration. With practice, it was possible to obtain an adequate specimen in less than three seconds from the time of insertion of the needle into the substance of the liver. Speed was desirable, since patients in severe acidosis were unable to hold their breath. The specimens were immediately fixed in iced absolute alcohol or Rossman's fixative.

Plasma carbon dioxide combining powers were determined by the method of Van Slyke and Neill (1). The Folin-Wu method was used for the determination of blood glucose (2).

\section{THE TECHNIC FOR THE ESTIMATION OF HEPATIC} GLYCOGEN

At first, the glycogen concentration was determined by the chemical method of Good, Kramer and Somogyi (3). This technic was unsatisfactory, however, since without histologic examination it was impossible to be

\footnotetext{
1 Presented in part at the Southern Section, American Federation for Clinical Research, New Orleans, La., January 26, 1948, and at the American Physiological Society, Atlantic City, N. J., March 18, 1948.
}

certain that the entire specimen submitted to analysis consisted of hepatic parenchyma. On several occasions, specimens obtained by needle biopsy have included bits of skeletal muscle, fat or fibrous tissue with the liver specimen. Had the entire contents of the needle been analyzed, the results would not have been representative of liver glycogen. It therefore seemed essential to examine microscopically the material which was to be analyzed. To do this, some histochemical method of estimating glycogen had to be adopted.

It had previously been shown by Deane, Nesbett and Hastings (4) that the staining intensity of glycogen in rat livers was proportional to the concentration of glycogen determined by the usual chemical methods. This fact was used to develop a method of estimating the glycogen content of the specimens obtained by biopsy.

The tissue was prepared and stained for glycogen by the method of Gomori (5) under carefully controlled uniform conditions. No counterstain was used. Control slides prepared from tissue digested by salivary amylase demonstrated that only glycogen-containing material was stained by this method.

The optical density of the stained glycogen was determined photometrically. A photomicrographic apparatus was set up in a dark room. The slide to be examined was placed upon the mechanical stage and its image projected, at a magnification of approximately $500 \times$ upon a ground glass screen with a central clear zone. Over the clear window was fixed the aperture of the photoelectric cell of a Photovolt electronic photometer. With the substage lamp turned off, the photometer was adjusted to read "0.0." The lamp was then turned on, and the slide scanned in an area without tissue. The substage diaphragm was then adjusted so that the photometer reading was "100.0." This step automatically corrects for variations of color or thickness of the slide, coverslip or mounting medium. The image of the preparation was then moved across the screen so that successive random readings of the light transmitted through the tissue could be made. Because of the manner of adjustment, the galvanometer readings represented "per cent transmission." These readings were translated to. optical density by the application of the formula: $d=2$ $-\log T$. Unstained tissue had no detectable optical density. Since glycogen stains black by the method used, it was possible to make readings using a white source of light without filters. A method similar to this has. 


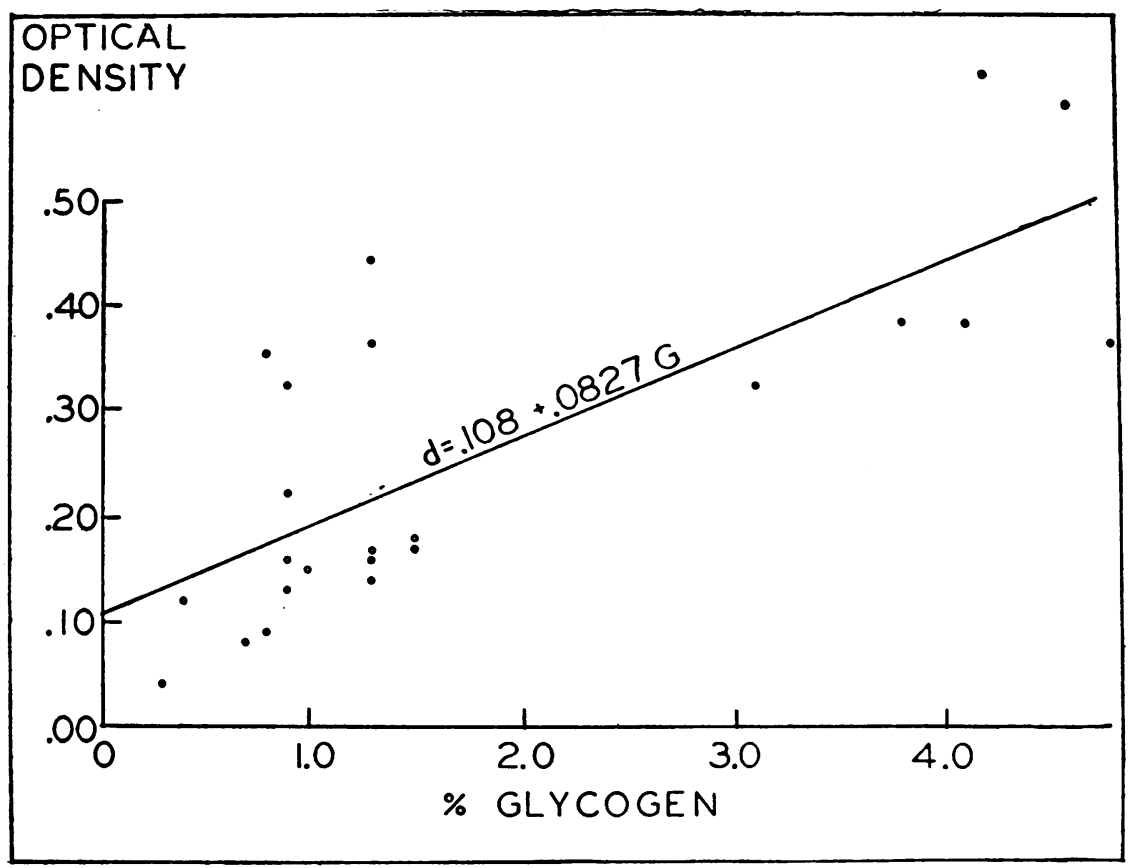

Fig. 1. Relationship of Optical Density of Histochemical Preparation to Glycogen Content of Rat Livers

been described by Buchanan and Hill for the estimation of myelin (6).

It has been observed by Gomori and Goldner (7) that there may be considerable focal variation of the glycogen content of liver cells. Hédon and Loubatières, however, analyzing fairly large aliquots of liver, have shown (8) the maximal variation within the liver to be less than 10 per cent. It was necessary, therefore, to determine the mean of a series of readings for each specimen in order to obtain an adequate sampling of the glycogen content of the specimen. The minimum number of observations which would afford the desired accuracy was ascertained by making 100 random readings of a single specimen. With 100 readings, the mean was 0.39 with a standard error of \pm 0.012 optical density units. With 20 readings, the standard error ranged from .014 to .022 . Ten readings produced standard errors ranging from 0.026 to 0.043 . It was felt that the standard error of less than 10 per cent provided by 20 readings was suffciently accurate for the purposes of the present investigation.

In order to estimate the accuracy of the method, a series of determinations were made comparing the chemical methods of assaying glycogen with the results of the histochemical estimation on the same specimen. A group of rats was injected with glucose whereas others were fasted for various periods to provide liver tissue with varying glycogen contents. The animals were then sacrificed. Immediately after death, adjacent specimens of liver were obtained for the determination of glycogen by the method of Good, Kramer and Somogyi (3) and for histochemical preparations. The regression of optical density on the chemical glycogen value was calculated. The significance of the regression was determined by dividing the slope by its standard error, giving a value of $p^{2}$ of less than 0.01 (Figure 1). The standard deviation of the points about the regression line was \pm 0.149 . It is of some importance that the standard deviation of the 100 readings performed on a single preparation was \pm 0.121 . In two separate sets of data, the degree of variance caused by the method of observation appears to be almost the same, indicating that the technic is uniform and the results reproducible.

A further conclusion may be drawn from the close agreement of the standard deviations of the regression curve and of a single preparation examined many times. Since the variance of the points about the regression curve is no greater than the variance of a series of optical densities determined for a single specimen, it appears that the entire scatter of points on the regression curve can be accounted for by the limitations of the method of determining optical density. It is therefore unnecessary to suppose that part of the scatter may be caused by unequal distribution of glycogen through the liver. Apparently the mean of 20 readings of the histologic section offers a sample adequate for controlling local variations of glycogen. The limiting factor of accuracy therefore appears to arise, not from the unequal distribution of liver glycogen, but from the limitations of the scanning technic.

2 " $p$ " estimated from Fisher's table of $p$ (23). A significant value is considered to be one less than 0.02 . Slope $=.0827 \pm .0031$. 
TABLE I

Therapeutic procedures and chemical determinations in sixpatients withdiabetic ketosis

\begin{tabular}{|c|c|c|c|c|c|c|c|c|c|c|}
\hline \multirow{2}{*}{ Patient } & \multirow{2}{*}{$\begin{array}{l}\text { Age } \\
\text { Sex }\end{array}$} & \multirow{2}{*}{$\begin{array}{l}\text { Pre- } \\
\text { plasma } \\
\text { CO, } \\
\text { comb. } \\
\text { power }\end{array}$} & \multicolumn{4}{|c|}{ Therapy until second biopsy } & \multicolumn{4}{|c|}{$\begin{array}{l}\text { Liver glycogen } \\
\text { gm. } / 100 \mathrm{gm} \text {. liver }\end{array}$} \\
\hline & & & Insulin & Glucose & Saline & $\begin{array}{l}\text { Interval } \\
\text { to second } \\
\text { biopsy }\end{array}$ & $\begin{array}{c}\text { Before } \\
\text { R }\end{array}$ & $\underset{\mathbf{R}}{\text { After }}$ & Increase & Increase \\
\hline & & vol. \% & units* & & & hours & & & & $\begin{array}{l}\underset{g m .}{g m . / 100} \\
\mathrm{gm.} / \mathrm{hr} .\end{array}$ \\
\hline G. H. & $\begin{array}{l}28 \\
M\end{array}$ & & \multicolumn{4}{|c|}{ No second biopsy was obtained } & 0.4 & & & \\
\hline P. C. & $\begin{array}{l}26 \\
F\end{array}$ & 19.1 & $\begin{array}{r}100 \\
50\end{array}$ & 100 & 2.0 & 1.00 & 0.3 & 0.6 & 0.3 & 0.3 \\
\hline M. S. & $\begin{array}{l}70 \\
F\end{array}$ & 48.7 & $45 \dagger$ & Lunch & 0.9 & 2.00 & 3.5 & 4.3 & 0.8 & 0.4 \\
\hline Gr. H. & $\begin{array}{l}35 \\
F\end{array}$ & 13.9 & $\begin{array}{r}150 \\
50\end{array}$ & 150 & 4.0 & 2.75 & 7.0 & 8.0 & 1.0 & 0.4 \\
\hline Br. T. & $\begin{array}{l}20 \\
\mathrm{M}\end{array}$ & 38.5 & 150 & 100 & 3.0 & 3.75 & 1.9 & 3.7 & 1.8 & 0.5 \\
\hline B. T. & $\begin{array}{l}40 \\
F\end{array}$ & 27.8 & $\begin{array}{l}250 \\
125\end{array}$ & 300 & 8.0 & 6.00 & 0.5 & 4.8 & 4.3 & 0.7 \\
\hline
\end{tabular}

* The upper figure refers to total dosage; the lower figure is the amount given intravenously in the clyses. Unless otherwise specified all insulin was regular insulin.

$\dagger$ Administered as a routine injection of protamine zinc insulin five hours before the biopsy.

The standard error of the glycogen determination is approximately \pm 0.022 . The limitation of the ability of the method to distinguish differences of glycogen concentration is, therefore, $\pm 0.044 d$ in the regression equation, $d=0.108+0.0827 \mathrm{G}$, or a difference of glycogen concentration of $0.5 \mathrm{gm} . / 100 \mathrm{gm}$. of liver. The sensitivity of this technic is therefore limited, since it cannot detect small alterations of concentration. This disadvantage seems to be outweighed by the opportunity to examine under the microscope the tissue which is to be analyzed, and by the assurance that it is the glycogen concentration of the liver cells which is actually being determined.

New sets of histologic preparations were made from the same blocks of rat liver for repeated histochemical assays. It was found that the slope of the regression curve varied somewhat in the different sets. In spite of this, the relationship of the various samples to one another remained constant. The variation of the slope therefore appeared not to be due to errors of the method of determining optical density, but to variations in the intensity of staining reaction in successive runs of slides. To control this, it was necessary to set up a new reference curve for the calibration of each batch of histologic preparations. This was done by running sections from four of the rat liver preparations previously described along with the biopsy specimens, taking care to treat both standards and unknowns in a uniform manner with regard to sectioning, staining and mounting. The optical densities of the standards were plotted, an estimated regression line drawn, and the glycogen content of the unknown specimens read from this line. All of the biopsies from a given subject were analyzed in the same batch.

\section{CLINICAL MATERIAL}

Six patients admitted to the medical service of Grady Memorial Hospital with diabetic acidosis of varying degrees of severity were subjected to needle biopsy of the liver before the institution of treatment. In five cases a second biopsy was obtained after varying periods of therapy. No ill effects attributable to biopsy were observed. The treatment used consisted of the administration of insulin, glucose and salt solutions. The details. are given in Table $\mathrm{I}$.

Liver biopsies by the same technic were also done on three patients hospitalized for various acute illnesses not. involving the liver or carbohydrate metabolism. The first biopsy was done under basal conditions and was followed by another biopsy in two of these patients after they had been given a standard breakfast which supplied more than $50 \mathrm{gm}$. of carbohydrate. At the time of these examinations, all patients were convalescent and had been afebrile for more than 48 hours. All had been eating a diet containing more than $300 \mathrm{gm}$. of carbohydrate for three or more days before the test.

\section{RESULTS}

The values obtained in the normal basal individuals were $2.8,3.2$ and $4.7 \mathrm{gm} . / 100 \mathrm{gm}$. These values are somewhat higher than the mean value of 2.0 per cent found by Young, Abels and Homburger (9) who obtained their specimens during laparotomy, and by Hildes, Sherlock and Walshe 
(10) who employed the aspiration biopsy technic and used a chemical technic for analysis of glycogen content. The present figures, however, fall within the range of normal observations obtained in both of the other normal series. Two subjects were examined one hour after breakfast. In these instances there was an increase of glycogen content of 1.5 and $2.3 \mathrm{gm} . / 100 \mathrm{gm}$. No comparable observations are available in intact human beings, since the results of Young, Abels and Homburger after the administration of glucose were obtained from patients other than those furnishing specimens prior to carbohydrate administration.

The glycogen content of the livers of patients with untreated diabetic ketosis ranged from 0.3 to $7.0 \mathrm{gm} . / 100 \mathrm{gm}$. (Table I). If patient $\mathrm{Gr}$. $\mathrm{H}$. is omitted from the calculation, there is a correlation between the carbon dioxide combining power and the liver glycogen concentration. The justification for the elimination of patient Gr. H. from this series is discussed below.

In each patient there was an elevation of the liver glycogen after treatment. If the rate of increase of glycogen in $\mathrm{gm} . / 100 \mathrm{gm} . / \mathrm{hr}$. is calculated for each patient, and compared with the duration of treatment before the second biopsy, a steady increase in the rate of glycogen deposition is found from a minimum of $0.3 \mathrm{gm} . / 100 \mathrm{gm} . / \mathrm{hr}$. after one hour of treatment, to a maximum of $0.72 \mathrm{gm} . /$ $100 \mathrm{gm} . / \mathrm{hr}$. after six hours of therapy.

\section{DISCUSSION}

The finding of normal values for the glycogen content of the liver under basal conditions presents additional evidence of the validity of the method used for estimating glycogen in the present study. The fact that the values range somewhat higher than the mean values of other series may be fortuitous in view of the small number of observations. It should be noted, however, that in the series presented by Young et al. (9) the patients received "routine preoperative preparation," which may have included morphine. Most of their specimens were obtained during laparotomy under ether anesthesia. The absence of pharmacologic and psychic stimulation prior to biopsy in the present series may account for the somewhat higher glycogen values in our patients.

The livers of untreated diabetic patients contained less glycogen than normal, except in two cases. One patient, M. S., was mildly decompensated. Her carbon dioxide combining power was almost normal (48.7 vol. per cent), and she recovered spontaneously under the influence of the protamine zinc insulin which she had taken five hours previously. The other patient, Gr. H., may represent a special case, and is discussed below. If this patient is omitted from consideration, there is a correlation between the carbon dioxide combining power and the liver glycogen concentration $(r=0.939 ; p$ less than 0.02). It therefore appears that the degree of glycogen depletion may have been related to the severity of the acidosis in five of the six patients.

It has generally been stated that the liver glycogen tends to be depressed in diabetic acidosis (11). It has been shown, however, that the liver glycogen of the pancreatectomized dog (12) or alloxanized rat $(13,14)$ or rabbit $(14)$ may be normal at times when the animal shows signs of severe diabetes. Glycosuria, hyperglycemia and ketonuria may be found in the presence of normal or elevated liver glycogen concentrations. In fact, alloxan-diabetic rats tend to maintain their liver glycogen reserves better during fasting than the normal rat (15). Only when the animal enters a stage of terminal acidosis does the glycogen level fall (16).

Previous studies of liver glycogen concentration in human diabetics have been confusing because the tissue was examined only after death $(17,18)$ or because, in many cases, the specimens were obtained after treatment with insulin (19, 20). Hildes et al. (10), using a technic similar to that used in the present study, determined the glycogen content of the liver of several diabetic patients. Their subjects, although ketonuric, were not severely decompensated, since there was only one in the group with a carbon dioxide combining power of less than 49 vol. per cent. In their series, the liver glycogen concentrations were normal.

The present series represents the first group of human diabetics in severe acidosis whose liver glycogens have been estimated prior to treatment. The relationship between the severity of acidosis and the depression of liver glycogen appears to agree with the results obtained in animals. It is of interest, however, that one patient (Gr. H.) had an elevated liver glycogen concentration while in severe acidosis. Thus, in humans as in ani- 
mals, it is possible to have advanced diabetic ketosis in the presence of an elevated liver glycogen concentration.

There is probably, therefore, no causal relationship between depression of liver glycogen and the development of acidosis in diabetes. On the contrary, the nausea and vomiting of ketosis may so restrict the food intake as to play a significant role in the development of liver glycogen depletion. We have no evidence upon which to decide which factor is primary.

After the institution of treatment, there was an increase in the hepatic glycogen concentration in all patients examined. This effect of therapy had previously been noted, in a qualitative observation (21). Following the institution of therapy, the rate of glycogen accumulation by the liver increased over a seven-hour observation period. This finding agrees with the studies of splanchnic glucose balance in human beings during treatment for diabetic ketosis (22). In these patients, there was a latent period of approximately one hour after the administration of large amounts of insulin intravenously before the splanchnic system began to retain glucose. It appears probable that even after the administration of large doses of insulin and glucose, some time must elapse before the liver achieves its maximal rate of glycogen deposition.

One patient, Gr. H., had a liver glycogen concentration far higher than any of the others, and higher than any of the normal subjects in this or other series $(9,10)$. There can be no doubt that the patient was suffering from severe diabetic acidosis (see appended case history). In certain respects, however, she was different from the other patients in the series. She was very obese, while the other patients were thin or normal in nutrition. The history of polyuria and polydipsia extended back for a period of two years; but she had felt well until, following a trauma, she suddenly developed ketosis. Her acidosis was moderately insulin-resistant, requiring more than 800 units in 24 hours; but when placed on a stringent reducing diet, she lost $20 \mathrm{lbs}$. and was controlled well without insulin. The other patients in this series had taken insulin for prolonged periods, and could not be controlled by diet alone. It therefore seems that patient Gr. H. falls into the group of mild diabetics with obesity. The other patients appear to have suffered from a more severe and, possibly, a basically different type of disease. It may be that this difference explains the fact that, of all the patients examined, only patient Gr. $\mathrm{H}$. had an elevated liver glycogen concentration during severe ketosis.

\section{SUMṀARY}

The liver glycogen content of diabetic and nondiabetic patients has been estimated by a method of determining the optical density of histologic preparations. The tissue was obtained by needle aspiration and was prepared by Gomori's histochemical technic. The method was sensitive to changes in glycogen concentration of $0.5 \mathrm{gm} . / 100 \mathrm{gm}$. and appeared to furnish an adequate estimate of the glycogen of the entire liver.

Glycogen determinations were made on the livers of three non-diabetic fasting patients, and in two of them after breakfast. The fasting values ranged from 2.8 to 4.7 per cent. A significant increase in the liver glycogen was observed after a meal.

Six decompensated diabetic patients were subjected to biopsy. In all cases except one, there was a decrease of liver glycogen proportional to the severity of the ketosis. After treatment, all patients showed an increase of liver glycogen.

One patient had a liver glycogen concentration of 7.0 per cent during severe ketosis. Because of her obesity and low insulin requirement, it is suggested that she may have had a type of diabetes different from the other subjects. In spite of her high initial glycogen level, this patient also deposited glycogen in her liver during therapy.

\section{APPENDIX}

Gr. H., 27 year old negress, was admitted to the medical service of Grady Memorial Hospital on February 14, 1948 , because of abdominal pain. She had noticed frequency of urination, beginning in 1945, and had moderate increase in thirst from that time. One week before admission she had been kicked in the abdomen. Following this, she developed abdominal pain, increased thirst and urination. Three days prior to admission she began to vomit. Eight hours before admission she developed shortness of breath.

One sister suffered from diabetes mellitus. The patient had adequately treated persistently seropositive syphilis. Two stillbirths had occurred, the most recent being three months before admission.

The temperature was 99.6 , pulse 110 , respirations 36 , blood pressure 120/80, and weight 247 lbs. The physical 
examination showed an uncomfortable, mildly disoriented obese negress who lay panting in bed. She was severely dehydrated. There were intertrigo, vaginitis and evidence of chronic pelvic inflammatory disease. The examination was otherwise not remarkable.

The Kahn test was positive (4 Kahn Units), the urine positive for sugar (four plus) and acetone (three plus). The red blood count was 5,850,000, the hematocrit 49 per cent and the sedimentation rate (Westergren) $48 \mathrm{~mm} . / \mathrm{hr}$. The white count was 11,550 , with 74 per cent polymorphonuclear forms. The admission blood glucose level was $420 \mathrm{mg} . / 100 \mathrm{ml}$,, and the carbon dioxide combining power 13.9 vol. per cent $(6.3 \mathrm{mM} / \mathrm{L})$.

The acidosis was controlled, in a period of 24 hours, after the administration of a total of 810 units of regular insulin, $6500 \mathrm{ml}$. of normal saline and $550 \mathrm{gm}$. of glucose parenterally. After a period of observation in the hospital, she was discharged on an 820 calorie reducing diet, with 60 units of protamine zinc insulin daily. Over a period of three months, her insulin requirement gradually dropped so that, by May 1948, she was aglycosuric without insulin. During this time she lost 20 lbs. of weight.

\section{BIBLIOGRAPHY}

1. Van Slyke, D. D., and Neill, J. M., The determination of gases in blood and other solutions by vacuum extraction and manometric measurement. J. Biol. Chem., 1924, 61, 523.

2. Folin, O., and Wu, H., A system of blood analysis. Supp. 1. A simplified and improved method for determination of sugar. J. Biol. Chem., 1920, 41, 367.

3. Good, C. A., Kramer, H., and Somogyi, M., The determination of glycogen. J. Biol. Chem., 1933, $100,485$.

4. Deane, H. W., Nesbett, F. B., and Hastings, A. B., Improved fixation for histological demonstration of glycogen and comparison with chemical determination in liver. Proc. Soc. Exper. Biol. \& Med., 1946, 63, 401.

5. Gomori, G., A new histochemical test for glycogen and mucin. Am. J. Clin. Path., Tech. Sect., 1946, 10, 177.

6. Buchanan, A. R., and Hill, R. M., Temperature regulation in albino rats correlated with determinations of myelin density in the hypothalamus. Proc. Soc. Exper. Biol. \& Med., 1947, 66, 602.

7. Gomori, G., and Goldner, M. G., Uneven distribution of glycogen in the liver. Proc. Soc. Exper. Biol. \& Med., 1947, 66, 163.

8. Hédon, L., and Loubatières, A., Dosage du glycogène dans de petits fragments de foie excisés au bistouri électrique; degré de precision de la technique; répartition du glycogène dans le foie du chien. Bull. Soc. chim. biol., 1938, 20, 910.
9. Young, N. F., Abels, J. C., and Homburger, F., Studies on carbohydrate metabolism in patients with gastric cancer. Defective hepatic glycogenesis; effects of adrenocortical extract. J. Clin. Invest., 1948, 27, 760.

10. Hildes, J. A., Sherlock, S., and Walshe, V., Liver and muscle glycogen in normal subjects, in diabetes mellitus and in acute hepatitis. I. Under basal conditions. Clin. Sc., 1949, 7, 287.

11. Duncan, G. G., Diabetes Mellitus, in: Duncan, G. G., Diseases of Metabolism. W. B. Saunders Co., Philadelphia, 1947, Ed. 2, p. 731.

12a. Minkowski, O., Untersuchungen über den Diabetes mellitus nach Exstirpation des Pankreas. Arch. f. exper. Path: u. Pharmakol., 1892, 31, 85.

b. Houssay, B. A., Biasotti, A., and Dambrosi, R. C., Glucogeno e hipofisis. Rev. Soc. argent. de biol., 1936, 12, 185.

13. Tuerkischer, E., and Wertheimer, E., Alloxan-diabetes and liver glycogen. J. Endocrinol., 1947, 5, 229.

14. Hard, W. L., and Carr, C. J., Experimental diabetes produced by alloxan. Proc. Soc. Exper. Biol. \& Med., 1944, 55, 214.

15. Weber, H., Carbohydrate metabolism in alloxandiabetic rats. Nature, 1946, 158, 627.

16. Kaplan, N. O., Franks, M., and Friedgood, C. E., Metabolism in diabetic coma produced by alloxan. Science, 1945, $102,447$.

17. Brian, E. W., Schechter, A. J., and Persons, E. L., Unusual glycogen storage in a case of diabetes mellitus. Arch. Int. Med., 1937, 59, 685.

18. Popper, H., and Wozasek, O., Zur Kenntnis der Glykogengehaltes der Leichenleber. II. Untersuchungen bei Diabetes mellitus. Ztschr. f. d. ges. exper. Med., 1931, 77, 414.

19. Stetson; R. P., and Ohler, W. R., Hepatomegaly and jaundice in a juvenile diabetic. New England J. Med., 1937, $217,627$.

20. Halliday, N., Lipid, carbohydrate and moisture content of the liver in diabetes mellitus. J. Lab. \& Clin. Med., 1940, 25, 926.

21. Bondy, P. K., and Sheldon, W. H., Histochemical demonstration of liver glycogen in human diabetic acidosis by liver biopsy. Proc. Soc. Exper. Biol. \& Med., 1947, 65, 68.

22. Bondy, P. K., Bloom, W. L., Whitner, V. S., and Farrar, B. W., Studies of the role of the liver in human carbohydrate metabolism by the venous catheter technic. II. Patients with diabetic ketosis, before and after the administration of insulin. J. Clin. Invest., 1949, 28, 1126.

23. Fisher, R. A., Statistical Methods for Research Workers. Oliver \& Boyd, London, 7th edition, 1938, p. 177. 